\title{
Associations between matrix metalloproteinase gene polymorphisms and glaucoma susceptibility: a meta-analysis
}

\author{
Ming-Yue $\mathrm{Wu}^{1,2+}$, Yang $\mathrm{Wu}^{3+}$, Yong Zhang ${ }^{4 \dagger}$, Cai-Yun Liu ${ }^{5}$, Chun-Yan Deng ${ }^{6}$, Le Peng ${ }^{2}$ and Lan Zhou ${ }^{2 *}$
}

\begin{abstract}
Background: Matrix metalloproteinases (MMPs) polymorphisms have been implicated in the pathogenesis of glaucoma risk. However, the results were controversial. We performed a meta-analysis to evaluate the precise associations between MMPs polymorphisms and glaucoma risk.

Methods: Related studies were reviewed by searching electronic databases within four databases. Odds ratios (ORs) with 95\% confidence intervals (Cls) were calculated to assess the association between the most common polymorphisms of MMPs and glaucoma risk. Heterogeneity, publication bias and sensitivity analysis were conducted to guarantee the statistical power.

Results: Overall, 11 selected articles involving 2,388 cases and 2,319 controls were included in this meta-analysis. Significant associations were only found between MMP-9 rs17576 G > A polymorphism (GA vs. GG: $\mathrm{OR}=0.80,95 \% \mathrm{Cl}=0$. 67-0.97, $P=0.02, I^{2}=0 \%$ ), MMP-9 rs3918249 C > T polymorphism (TT vs. $C C+C T: O R=0.71,95 \% C l=0.51-0.98, P=0.04$, $1^{2}=0 \%$ and glaucoma risk in the general population. Subgroup analysis also suggested that MMP-9 rs17576 G $>$ A was related to glaucoma in the Caucasian population (GA vs. GG: $\mathrm{OR}=0.67,95 \% \mathrm{Cl}=0.45-1.00, P=0.05 ; \mathrm{GA}+\mathrm{AA}$ vs. GG: $\mathrm{OR}=0.66,95 \% \mathrm{Cl}=0.45-0.97, \mathrm{P}=0.03, \mathrm{I}^{2}=0 \%$ ).
\end{abstract}

Conclusions: Our meta-analysis demonstrates that MMP-9 rs17576 G > A polymorphism might be a protective factor against the development of glaucoma in Caucasian population.

Keywords: Matrix metalloproteinases, Glaucoma, Polymorphism

\section{Background}

Glaucoma is a heterogeneous disease of the eye characterized by the progressive degeneration of retinal ganglion cells and loss of vision associated with elevated intraocular pressure (IOP) [1]. After cataracts, glaucoma is the second leading cause of blindness in the world [2]. In China, there were approximately 15.8 million patients with glaucoma in 2010 and the number of patients is projected to increase to 21.8 million by 2020 [3]. This visual disorder results in severe disability, a reduced quality of life, and a substantial economic burden for individuals and society.

\footnotetext{
*Correspondence: 1902764052@qq.com

${ }^{\dagger}$ Equal contributors

${ }^{2}$ Department of Neurology, Center for Evidence-Based Medicine and Clinical Research, Taihe Hospital, Hubei University of Medicine, 32 South Renmin Road, Shiyan 442000, China

Full list of author information is available at the end of the article
}

As we know, ocular hypertension is the most important risk factor for glaucoma, but its etiology is still unclear. Many molecular epidemiological studies have suggested that glaucoma is a complex multifactorial disease. Various risk factors such as diabetes, hypertension, lifestyle habits (e.g., smoking tobacco and drinking alcohol), age, and genetics play interacting roles in the development of glaucoma. Recently, certain genetic factors, including matrix metalloproteinases (MMPs), were found to be associated with glaucoma. MMPs are a group of zinc and calciumdependent endopeptidases that are involved in extracellular matrix (ECM) homeostasis and remodeling $[4,5]$. In glaucoma, pathological changes occur in the trabecular meshwork and the juxtacanalicular tissue of the chamber angle. Aqueous humor (AH) drainage is influenced by the ECM, which modulates $\mathrm{AH}$ outflow from the anterior chamber via the irido-corneal drainage angle to regulate 
IOP [6]. A recent study in animal models reported that the abnormal expression of MMPs in the AH of patients with glaucoma may influence the regulation of IOP [7]. These findings indicated that the aberrant expression of MMPs may be associated with both the development and prognosis of glaucoma.

Previous molecular research has demonstrated that genetic mutations, including single nucleotide polymorphisms (SNPs), can alter the level of gene expression or the function of gene products, thereby affecting the susceptibility of individuals to specific diseases [8,9]. In 2006, Wang et al. [10] reported an association between SNPs in the MMP-9 gene and the risk of developing glaucoma, and suggested that the rs17576 G > A mutation maybe a risk factor in Taiwanese patients. Subsequently, considerable efforts have been made to elucidate the relationship between MMP gene polymorphisms and glaucoma risk worldwide, but conflicting results have been observed. Therefore, we conducted a comprehensive meta-analysis to evaluate the association between MMP gene polymorphisms and glaucoma risk.

\section{Methods}

This meta-analysis was conducted according to the guidelines of Preferred Reporting Items for Systematic reviews and Meta-Analyses (PRISMA) [11, 12]. No ethical issues were involved in this study given that our data were based on published studies.

\section{Search strategy}

Four online databases (PubMed, Embase, CNKI, Wanfang) were used to search for case control studies evaluating the association between MMPs polymorphisms and glaucoma risk published up to February 1, 2016, with the following search terms: "glaucoma," "MMP," "matrix metalloproteinases," "polymorphism," and "variant". Manual searches of references from original studies and review articles on this topic were conducted to identify other relevant studies.

\section{Inclusion and exclusion criteria}

The inclusion criteria for studies in our meta-analysis were as follows: (1) designed as a case control study, (2) reported an association between MMP polymorphism(s) and glaucoma risk,(3) sufficient genotype frequency to estimate odds ratios (ORs) and 95\% confidence intervals (CIs), and (4) no deviation from Hardy-Weinberg equilibrium (HWE) in the genotype distribution of the control group. For results that were reported in multiple publications, only the largest or latest dataset was included. The exclusion criteria included: (1) review articles, (2) case reports, (3) results without sufficient genotype frequency data, and (4) animal model research.

\section{Data extraction}

Two reviewers (MYW and YW) independently reviewed the full articles and collected the following characteristics: the first author's name, publication year, study country/region, ethnicity of participants (such as Asian or Caucasian), disease subtype, genotyping method, sources of controls, and frequencies of genotypes in glaucoma cases and controls. Hardy-Weinberg equilibrium (HWE) was estimated based on the genotypes of the controls. Discrepancies were resolved by discussion between the 2 reviewers or by consulting with an expert in ophthalmology (ZY).

\section{Statistical analysis}

Crude ORs with 95\% CIs were calculated to evaluate the strength of the association between each reported MMP polymorphism and glaucoma risk. For the MMP-9 rs17576G > A polymorphism, the pooled ORs were obtained for the allele contrast (A vs. G), co-dominant (GA vs. GG,AA vs. GG), dominant (GA + AA vs. GG), and recessive (AA vs. GG + GA) models. Subgroup analyses according to disease type, ethnicity, study design, and genotyping methods were also conducted. Heterogeneity was assessed using Cochran's $Q$ statistic and the $\mathrm{I}^{2}$ method [13]. ORs estimation was calculated with a fixedeffects model (the Mantel-Haenszel method) when the P value was more than 0.10 or $\mathrm{I}^{2}$ was less than $50 \%$ [14]; otherwise, a random-effects model (the DerSimonian and Laird method) was adopted $[15,16]$. Cumulative metaanalyses and sensitivity analyses were conducted to evaluate the stability of the results by removing each study sequentially for each polymorphism. The potential publication bias of the literature was analyzed by Egger's linear regression and Begg's funnel plots. Similar genetic models were also assessed for the other MMP-1, 2, and 9 variants. Statistical analysis was performed using STATA version 11.0 (Stata Corporation, College Station, TX, USA) with 2 -sided $P$-values and $P<0.05$ was considered statistically significant.

\section{Results}

\section{Study characteristics}

In total, 45 related articles were identified. Seventeen of these studies were excluded through title and duplicate screening. Subsequently, 1 study was excluded for not involving glaucoma research; 2 studies without related polymorphisms locus were excluded; 6 studies were excluded for fundamental molecular biology researches; and 8 studies were excluded because they were reviews. Finally, 11 articles involving 2,388 cases and 2,319 controls met the inclusion criteria [10, 17-26] (Fig. 1). Among these included articles, 9 studies focused on associations between MMP-9 polymorphisms (rs17576 G > A, rs17577 G > A, rs3918249 C > T, rs3918242 C > T, rs3918254 C > 


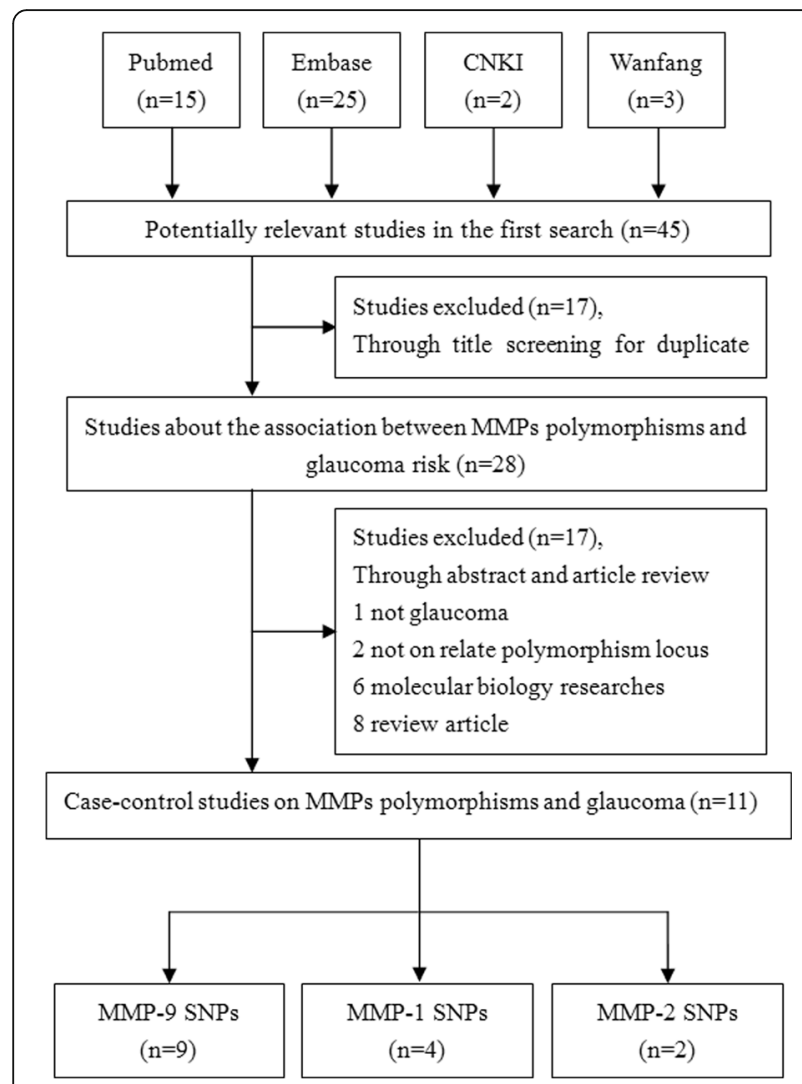

Fig. 1 Flow diagram of the study selection process

T, rs3787268 G > A) and glaucoma [10, 17-24] (Table 1), 4 articles on associations between an MMP-1 polymorphism (rs1799750 1G > 2G) and glaucoma [19, 22, 24, 25] (Table 2), and 2 articles on associations between an MMP-2 polymorphism (rs243865C $>\mathrm{T}$ ) and glaucoma $[19,26]$ (Table 2).

Five studies involved Asian populations [10, 17, 18, $21,23]$ and 6 studies involved Caucasian populations [19, 20, 22, 24-26]. No study deviated from HWE. The detailed characteristics of the selected studies are summarized in Tables 1 and 2 .

\section{Meta-analysis \\ Association between MMP-9 polymorphisms with glaucoma risk}

With regards to MMP-9 gene polymorphisms and glaucoma risk, 9 articles (reporting a total of 11 case-control studies) involving 2,028 cases and 1,794 controls were included in our analyses of the 6 most commonly reported SNP loci. Overall, significant associations were only found between MMP-9 rs17576 G > A polymorphism (GA vs. GG: $\mathrm{OR}=0.80,95 \% \mathrm{CI}=0.67-0.97, P=0.02$, $\mathrm{I}^{2}=0 \%$ ), MMP-9 rs3918249 $\mathrm{C}>\mathrm{T}$ polymorphism (TT vs. $\mathrm{CC}+\mathrm{CT}: \mathrm{OR}=0.71,95 \% \mathrm{CI}=0.51-0.98, P=0.04, \mathrm{I}^{2}=0 \%$ ) and glaucoma risk. Furthermore, in the subsequent analyses based on disease type, ethnicity, control design and genotyping methods, a significant protective effect against glaucoma risk was observed for MMP-9 rs17576 $\mathrm{G}>\mathrm{A}$ in Caucasian populations (GA vs. GG: $\mathrm{OR}=0.67$, $95 \% \mathrm{CI}=0.45-1.00, P=0.05, \mathrm{I}^{2}=0$ (Fig. 2 ); $\mathrm{GA}+\mathrm{AA}$ vs. GG: $\quad$ OR $\left.=0.66, \quad 95 \% \mathrm{CI}=0.45-0.97, \quad P=0.03, \quad \mathrm{I}^{2}=0 \%\right)$ (Table 3). No significant association was found between other MMP-9 polymorphisms and glaucoma risk.

Sensitivity analyses were conducted by deleting each included study step by step in MMP-9 rs17576 G > A polymorphism. No single study qualitatively changed the pooled ORs when removed, indicating that the results of this meta-analysis are stable (Fig. 3 for GA vs. GG model). Cumulative analysis showed that the protective effect increased gradually with the increase of sample size by publication date in MMP-9 rs17576 G > A polymorphism (Fig. 4 for GA vs. GG model). Funnel plots were performed to assess the potential for publication bias, and no evidence of asymmetry was found (Fig. 5 for GA vs. GG model). This result was further supported by analysis using Egger's test (A vs. G: $P=0.30$; GA vs. GG: $P=0.57$; AA vs. GG: $P=0.28$; GA + AA vs. GG: $P=0.95$; AA vs. GG $+\mathrm{GA}, P=0.43$ ), indicating that there was no detectable publication bias.

\section{Association between MMP-1 and MMP-2 polymorphisms with glaucoma risk}

Four articles (reporting a total of 6 case control studies) involving 1,065 cases and 836 controls and 2 articles (reporting a total of 3 case control studies) with 792 cases and 559 controls were included in our metaanalysis of the MMP-1 rs1799750 1G > 2G and MMP-2 rs243865 $\mathrm{C}>\mathrm{T}$ polymorphisms and glaucoma risk. No significant association was found for all models for these 2 SNP loci (Table 4). Subgroup analyses based on disease type and control design were also conducted, and no significant association was found.

\section{Discussion}

MMPs are classified as a large family of zinccontaining proteases and have been suggested to be important mediators in the pathogenesis of various diseases. MMPs, which are antagonized by tissue inhibitors of metalloproteinases (TIMPs), can degrade and remodel ECM molecules, thereby influencing cellular activities and maintaining the homeostasis of theepithelialbasementmembrane [27, 28]. The abnormal expression of MMPs can disturb the proteolytic balance and result in a number of pathologic conditions such as inflammatory diseases [29], oropharyngeal cancer [30], coronary heart disease [31], and respiratory abnormalities [32]. In the development of glaucoma, an imbalance between MMPs and TIMPs may impair ECM turnover in the trabecular 


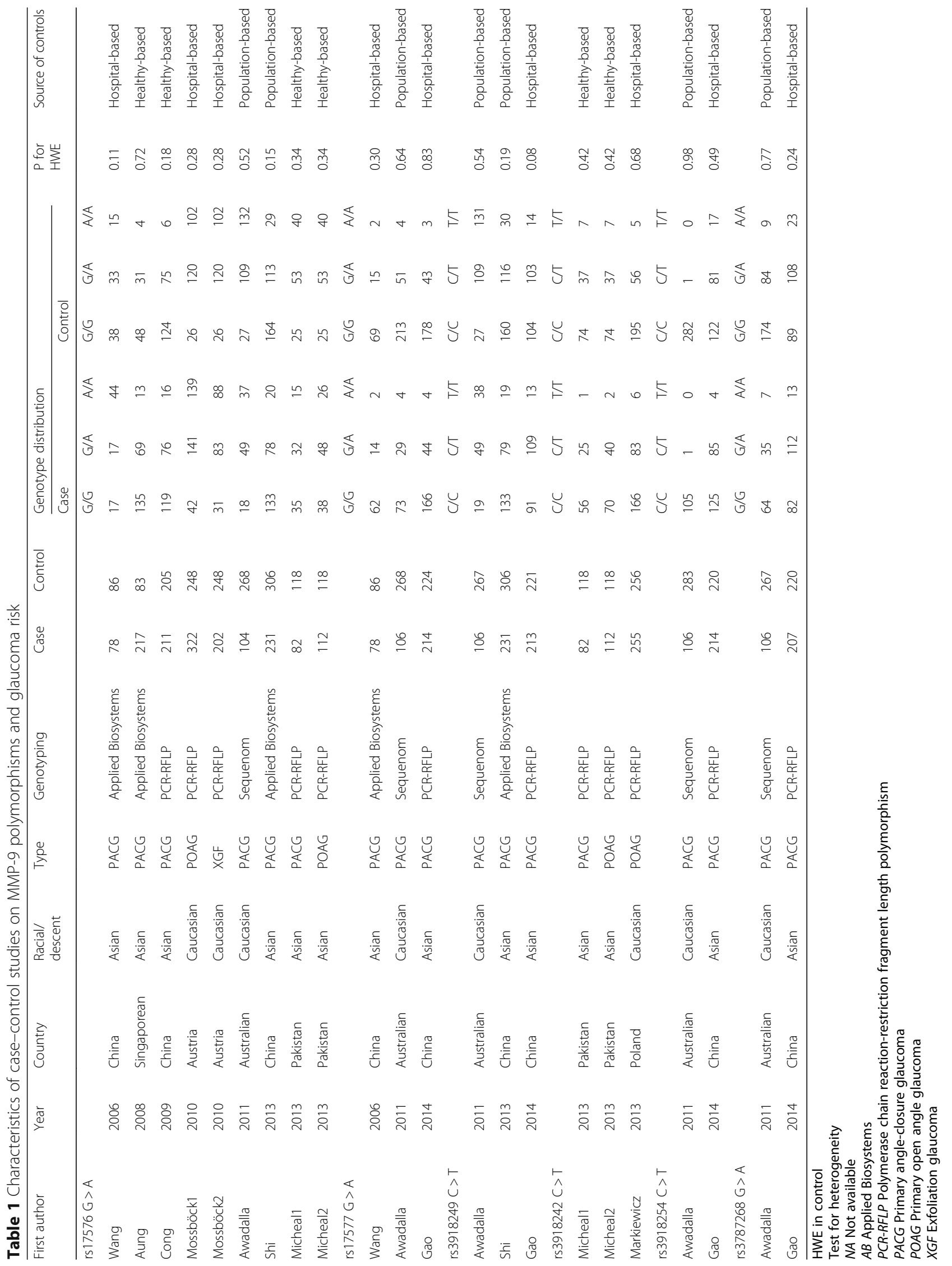


Table 2 Characteristics of included studies on MMP-1 rs1799750 1G > 2G and MMP-2 rs243865C > T polymorphisms and glaucoma risk

\begin{tabular}{|c|c|c|c|c|c|c|c|c|c|c|c|c|c|c|c|}
\hline \multirow{3}{*}{$\begin{array}{l}\text { First author } \\
\text { rs1799750 1G > 2G }\end{array}$} & \multirow[t]{3}{*}{ Year } & \multirow{3}{*}{ Country } & \multirow{3}{*}{$\begin{array}{l}\text { Racial/ } \\
\text { descent }\end{array}$} & \multirow[t]{3}{*}{ Type } & \multirow[t]{3}{*}{ Genotyping } & \multirow[t]{3}{*}{ Case } & \multirow[t]{3}{*}{ Control } & \multicolumn{6}{|c|}{ Genotype distribution } & \multirow{3}{*}{$\begin{array}{l}\text { P for } \\
\text { HWE }\end{array}$} & \multirow{3}{*}{$\begin{array}{l}\text { Source of } \\
\text { controls }\end{array}$} \\
\hline & & & & & & & & \multicolumn{3}{|l|}{ Case } & \multicolumn{3}{|l|}{ Control } & & \\
\hline & & & & & & & & $1 \mathrm{G} / 1 \mathrm{G}$ & $1 \mathrm{G} / 2 \mathrm{G}$ & $2 \mathrm{G} / 2 \mathrm{G}$ & $1 \mathrm{G} / 1 \mathrm{G}$ & $1 \mathrm{G} / 2 \mathrm{G}$ & $2 \mathrm{G} / 2 \mathrm{G}$ & & \\
\hline Tsironi & 2009 & Greece & Caucasian & XFG & PCR-RFLP & 92 & 214 & 39 & 42 & 11 & 65 & 110 & 39 & 0.53 & Hospital-based \\
\hline Mossböck1 & 2010 & Austria & Caucasian & POAG & PCR-RFLP & 322 & 248 & 42 & 141 & 139 & 26 & 120 & 102 & 0.28 & Hospital-based \\
\hline Mossböck2 & 2010 & Austria & Caucasian & XFG & PCR-RFLP & 202 & 248 & 31 & 83 & 88 & 26 & 120 & 102 & 0.28 & Hospital-based \\
\hline Markiewicz & 2013 & Poland & Caucasian & POAG & PCR-RFLP & 255 & 256 & 93 & 77 & 85 & 94 & 113 & 49 & 0.15 & Hospital-based \\
\hline Micheal1 & 2013 & Pakistan & Asian & PACG & PCR-RFLP & 82 & 118 & 25 & 36 & 21 & 53 & 45 & 20 & 0.06 & Healthy-based \\
\hline Micheal2 & 2013 & Pakistan & Asian & POAG & PCR-RFLP & 112 & 118 & 27 & 49 & 36 & 53 & 45 & 20 & 0.06 & Healthy-based \\
\hline rs $243865 C>T$ & & & & & & & & $\mathrm{C} / \mathrm{C}$ & $C / T$ & $T / T$ & $\mathrm{C} / \mathrm{C}$ & $C / T$ & $T / T$ & & \\
\hline Mossböck1 & 2010 & Austria & Caucasian & POAG & PCR-RFLP & 322 & 248 & 187 & 111 & 24 & 138 & 88 & 22 & 0.15 & Hospital-based \\
\hline Mossböck2 & 2010 & Austria & Caucasian & XFG & PCR-RFLP & 202 & 248 & 107 & 80 & 15 & 138 & 88 & 22 & 0.15 & Hospital-based \\
\hline Kaminska & 2014 & Poland & Caucasian & POAG & PCR-RFLP & 268 & 311 & 159 & 89 & 20 & 175 & 123 & 13 & 0.13 & Hospital-based \\
\hline
\end{tabular}

HWE in control

Test for heterogeneity

PCR-RFLP Polymerase chain reaction-restriction fragment length polymorphism

PACG Primary angle-closure glaucoma

meshwork and increase the resistance to $\mathrm{AH}$ outflow, which may eventually lead to raised IOP and glaucoma [33].

SNPs are the most common type of genetic mutation and have been associated with altered disease susceptibility through changes in gene transcription and expression as well as amino acid substitutions. In 2006, Wang et al. conducted the first case control study investigating the potential association between MMP-9 SNPs and primary angle-closure glaucoma.
Significant differences in the frequencies of the MMP-9 rs17576 G > A SNP genotypes were found between the glaucoma and healthy control groups, which suggested an increased risk for glaucoma in the Chinese population according to a dominant model $(\mathrm{OR}=2.84,95 \% \mathrm{CI}=1.63-5.64, P=0.03)$. Subsequently, more epidemiological studies were conducted, with inconsistent and even contradictory results.

In this meta-analysis, published research data were pooled and analyzed to investigate a specific research

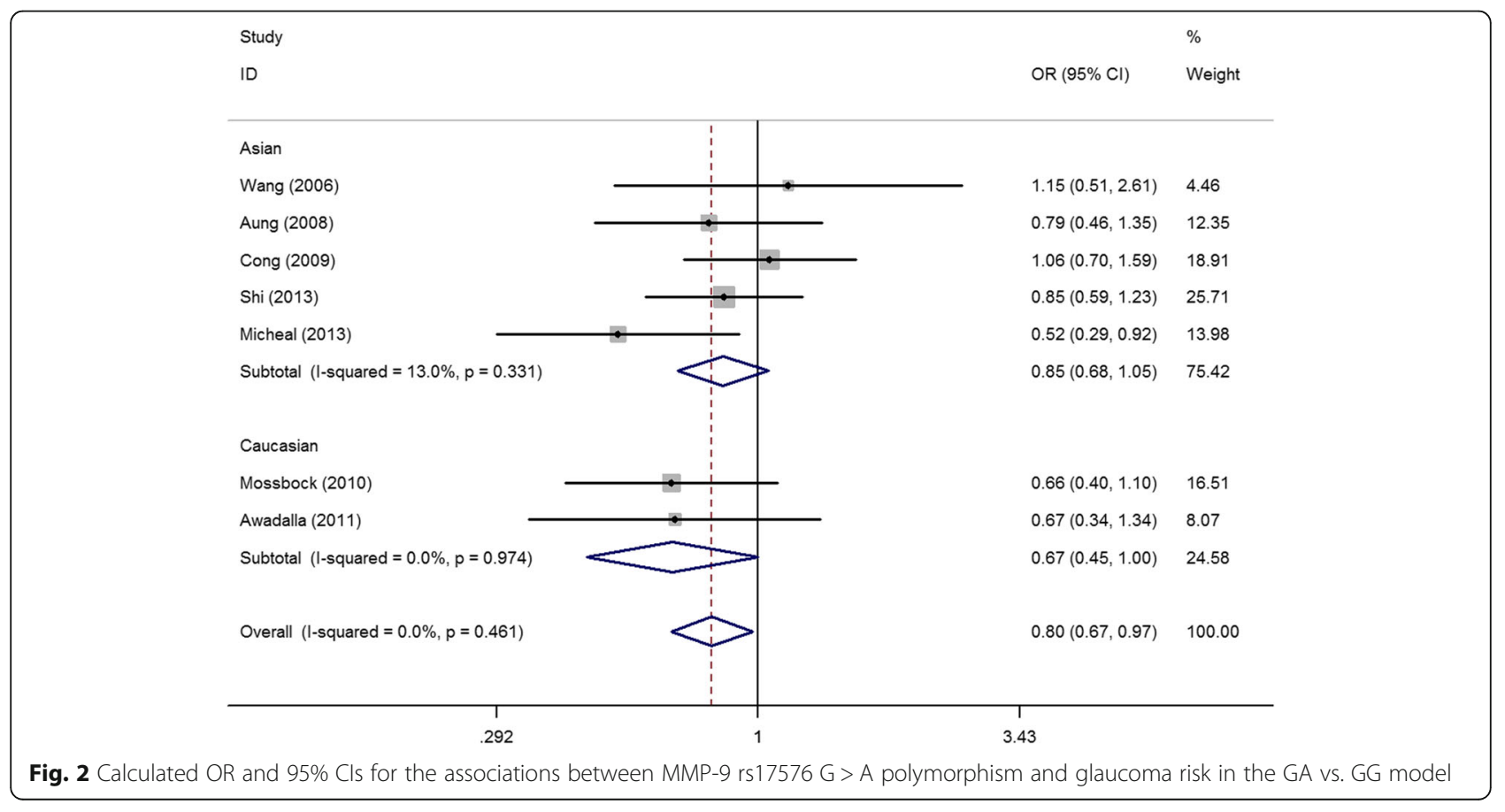




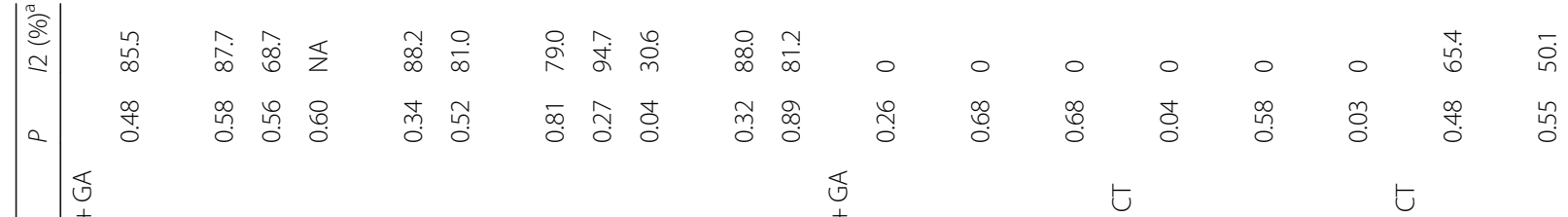

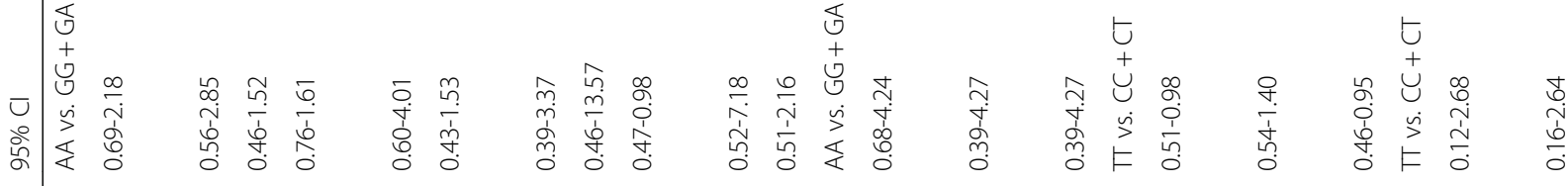

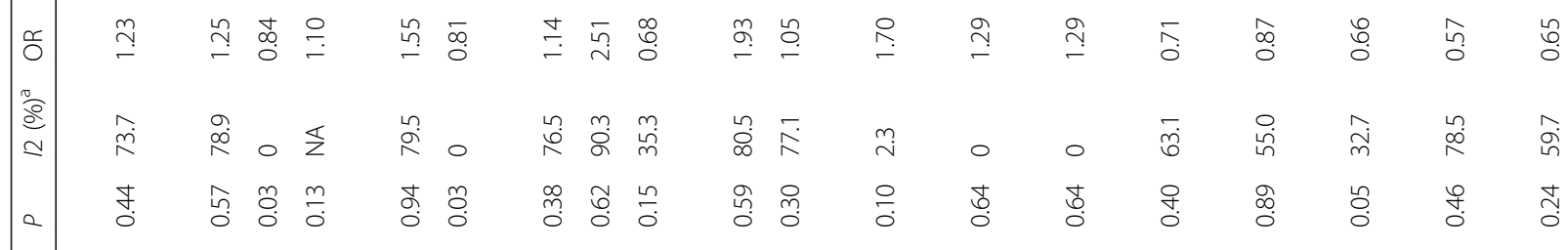 Uु

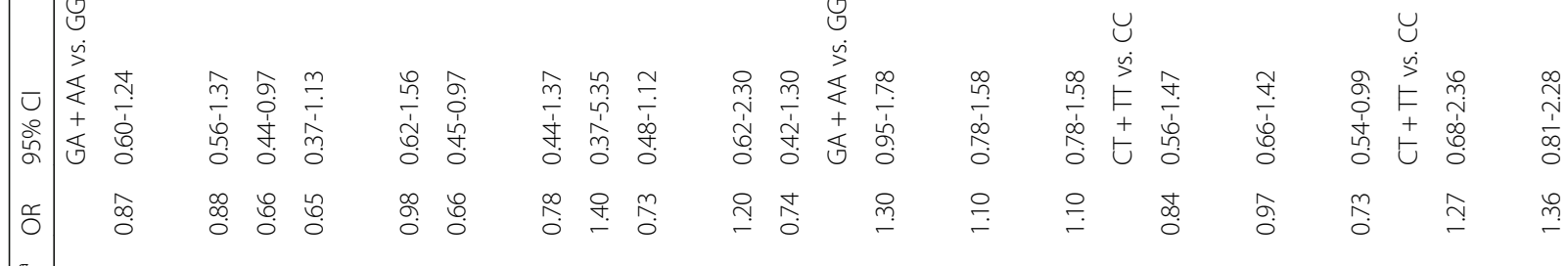

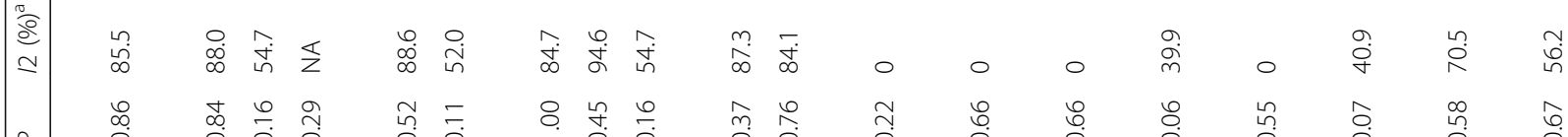

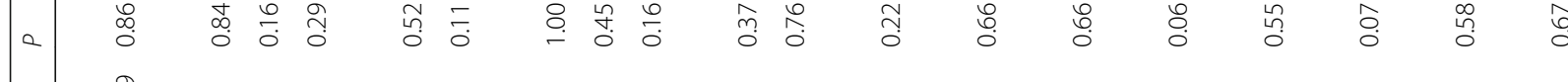

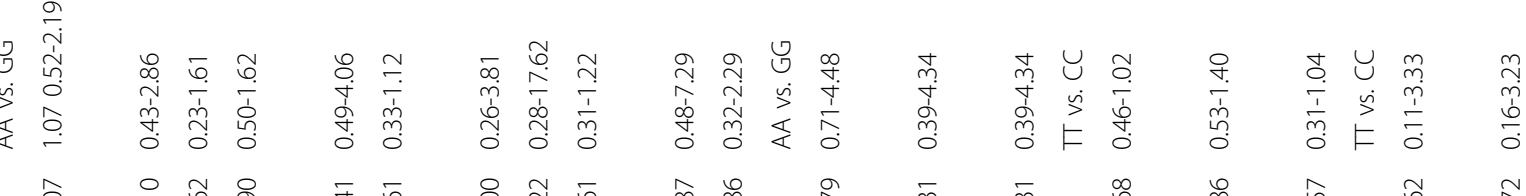

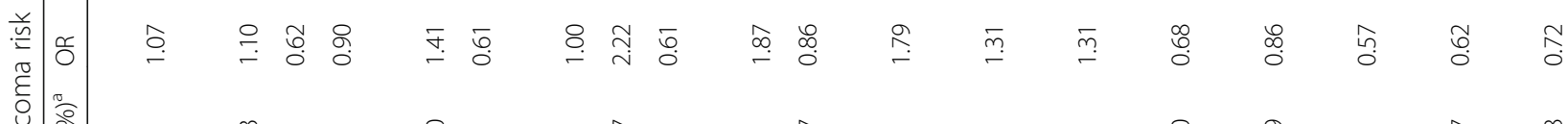

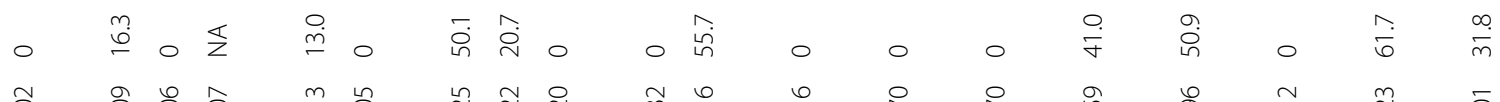 䓀

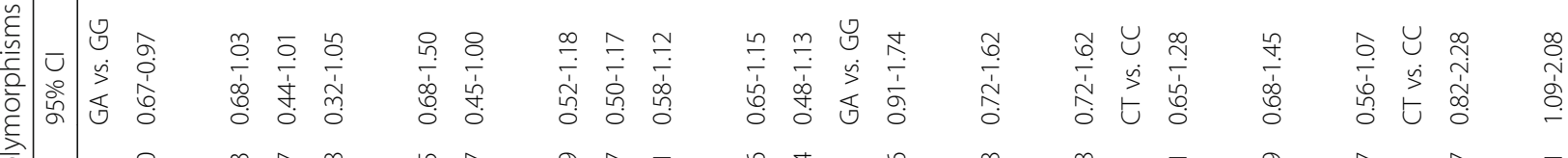 商

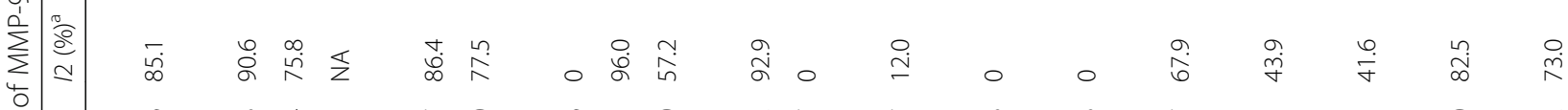

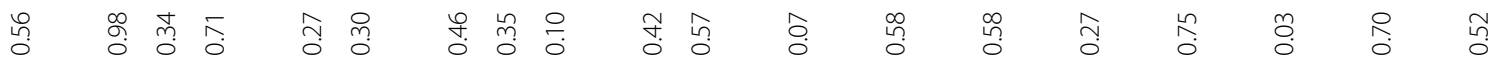 疋

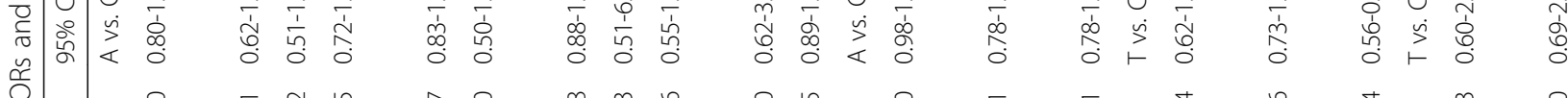

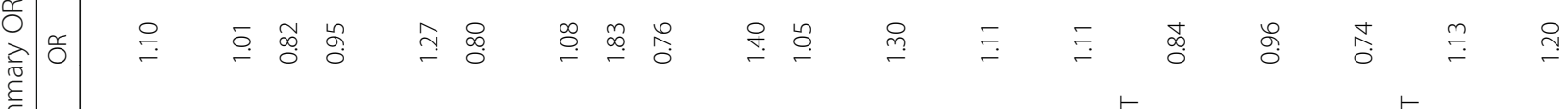

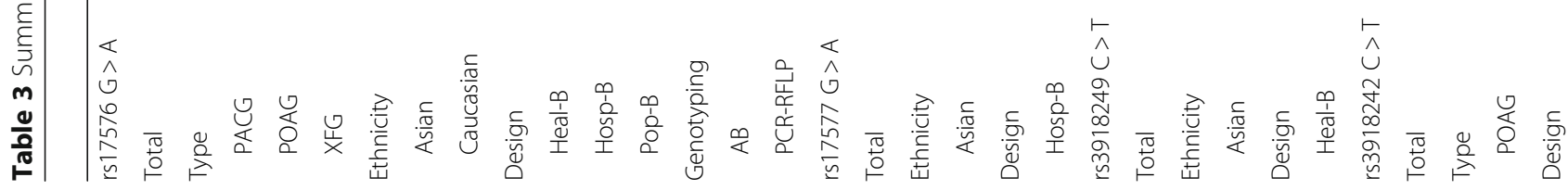




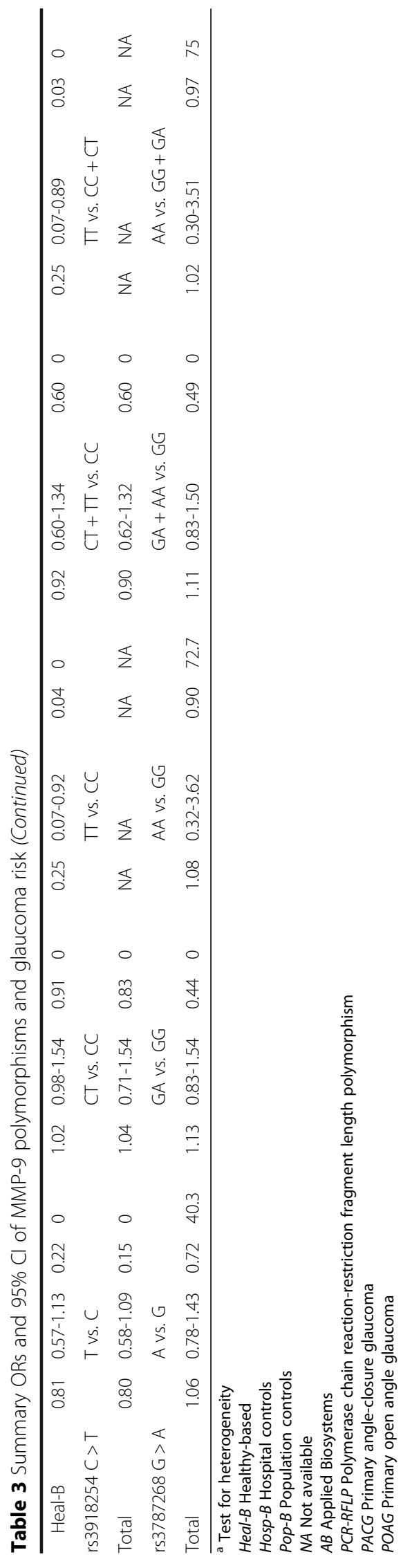




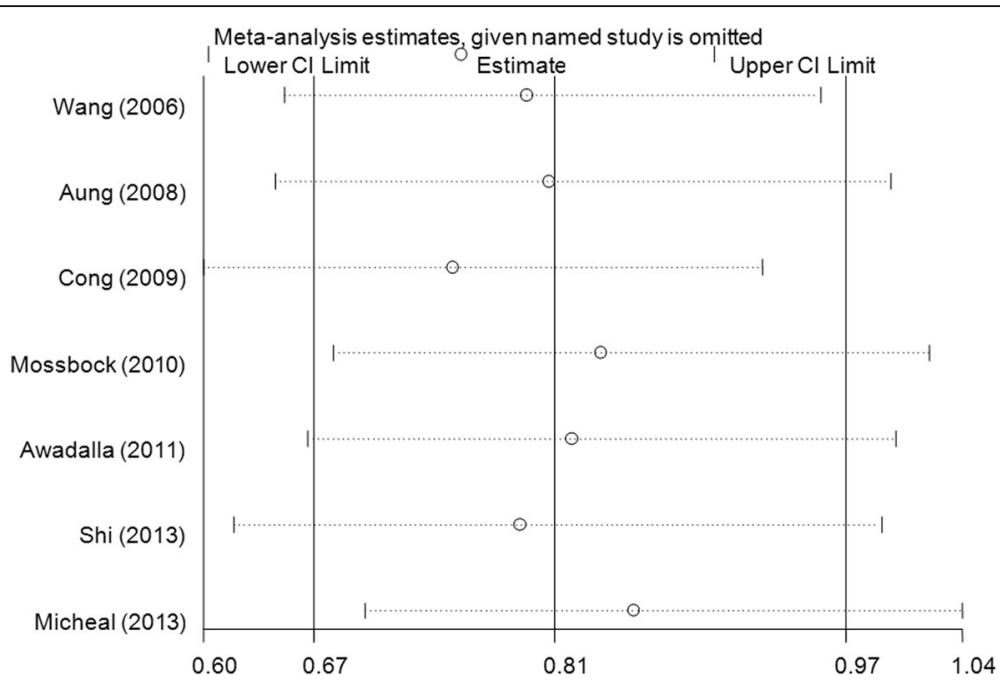

Fig. 3 Sensitivity analysis via deletion of each individual study reflects the relative influence of each individual dataset on the pooled ORs in the GA vs. GG model of MMP-9 rs17576 G > A polymorphism and glaucoma risk

question. Pooling datasets reduces the random error that can occur with small sample sizes. This retrospective review indicated that an inadequate number of studies, small sample sizes and limited ethnic diversity, contributed to their conflicting findings. To evaluate the evidence for the potential association between MMPs and glaucoma susceptibility, we conducted this meta-analysis using 2,388 cases and 2,319 controls from 11 publications. Overall, our analysis indicated that MMP-9 polymorphisms (rs17576 G > A and rs3918249 $\mathrm{C}>\mathrm{T}$ ) conferred different significantly susceptibility to glaucoma. Stratified analysis by ethnicity, control design, and genotyping method were performed to estimate the association for each subgroup. The subgroup analysis according to ethnicity demonstrated a significant protective association between the MMP-9 rs17576 G>A polymorphism and glaucoma susceptibility in the Caucasian population. Thus, ethnic differences may be the most important factor underlying differences in glaucoma susceptibility between the Asian and Caucasian populations. MMP-9 rs17576 polymorphism is locate in exon 6 of

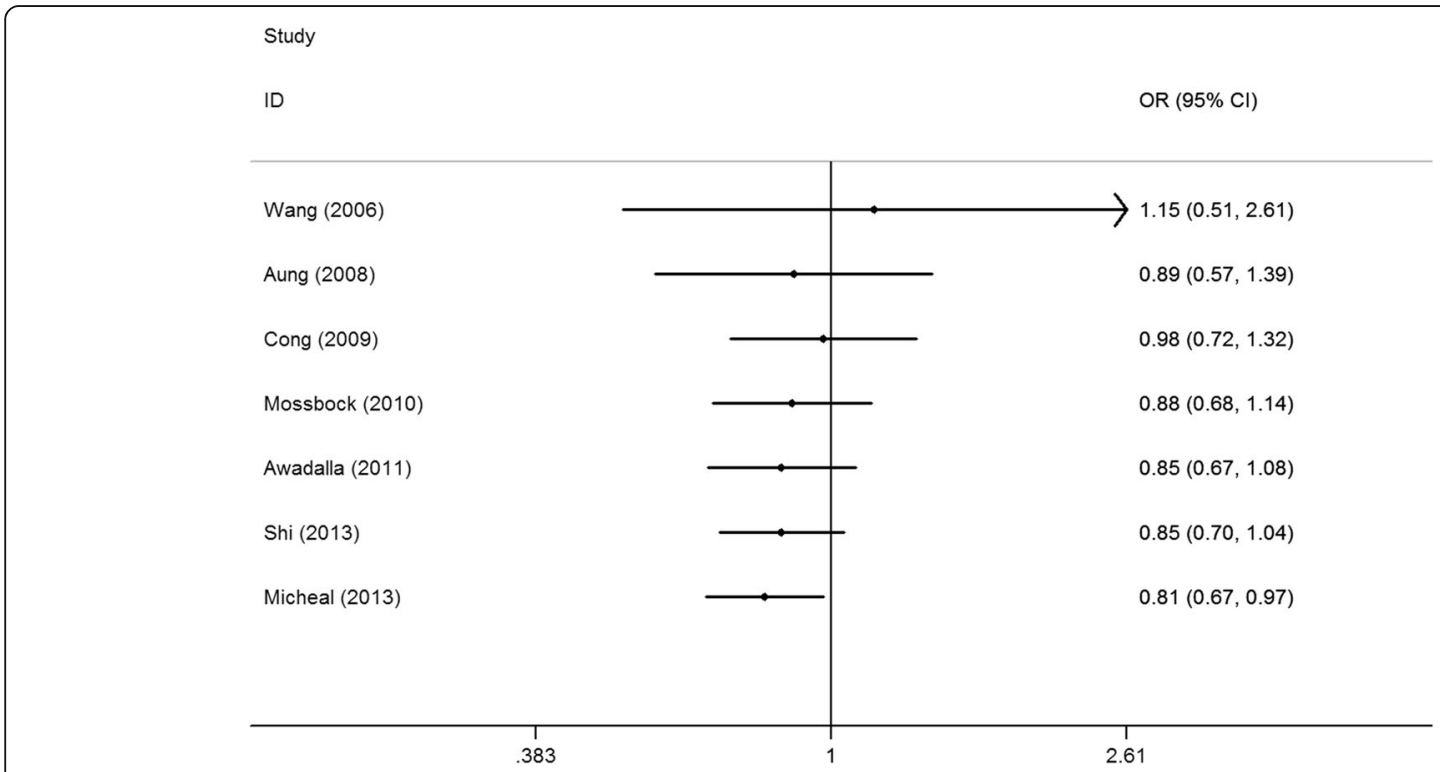

Fig. 4 Cumulative meta-analyses according to publication year in the GA vs. GG model of MMP-9 rs17576 G > A polymorphism and glaucoma risk 


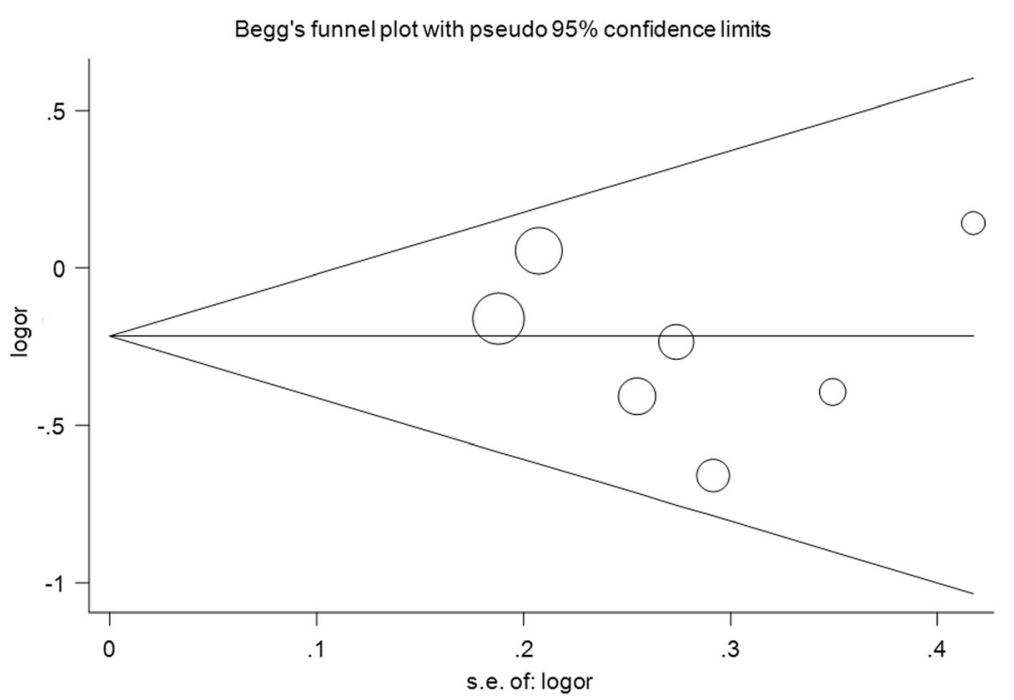

Fig. 5 Funnel plot analysis to detect publication bias for GA vs. GG model of MMP-9 rs17576 G > A polymorphism and glaucoma risk. Circles represent the weight of the studies

MMP-9 gene with a nucleic acid substitution from $G$ to $\mathrm{A}$, and this mutation located fibronectin type II domains that presumably enhance substrate binding $[34,35]$. Although no experimental research on this polymorphism was reported. The conversion from the positively charged amino acid arginine to uncharged glutamine may influence the activity of this enzyme and affect the glaucoma susceptibility [36, 37]. As we know, the pathogenesis of primary open-angle glaucoma (POAG)、 primary closure-angle glaucoma (PACG) and exfoliation syndrome (XFG) are not identical. PACG is characterized by the adhesion between the peripheral iris and trabecular meshwork, resulting in the inability of the aqueous fluid to flow out of the aqueous humor. POAG is thought to be a common glaucoma, accompanied with optic neuropathy and corresponding visual field progressive damage with an open situation of anterior chamber angle. The etiology of XFG is still unknown,which generally believed to be a systemic disorder of eye condition. They are caused by intermittent or persistent elevation of IOP, resulting in damage to the eye tissue and visual function. In this meta-analysis,subgroup analysis of POAG、PACG and XPF risk were conducted in only two polymorphism loci due to the small sample size of included studies. Regrettably, this study failed to find a direct correlation between the MMPs genetic polymorphisms and the three sub-diseases.

To the best of our knowledge, this is the first comprehensive meta-analysis evaluating the potential association between MMP gene polymorphisms and glaucoma susceptibility. Some limitations of this meta-analysis were inevitable and should be addressed. First, the number of included studies and the amount of data available were limited, which constrained the statistical power. Second, heterogeneity was observed in the data for some SNP loci, which further hindered our ability to confidently identify any potential associations. Third, due to the deficiency of available data, it was not possible to study the interactions between MMP gene SNPs and glaucoma risk factors, such as haplotype, tobacco smoking, alcohol drinking, hypertension, and diabetes mellitus.

Despite these limitations, the findings further enhance our understanding of the potential associations between MMP gene polymorphisms and glaucoma susceptibility. Positive aspects of the analysis were also identified. First, the distributions of genotypes in the control subjects for all of the investigated SNPs conformed to HWE. Second, evaluation using Egger's test and Begg's funnel plots did not show significant publication bias. Third, a large amount of heterogeneity was alleviated through subgroup analyses.

\section{Conclusion}

In conclusion, our meta-analysis indicated that the MMP-9 rs17576 G > A polymorphism maybe an important protective factor against glaucoma, especially in the Caucasian population. Moreover, the present findings highlight the need for further investigations of the potential associations between MMP gene polymorphisms and glaucoma, which should ideally large sample sizes and multiple ethnic groups. 


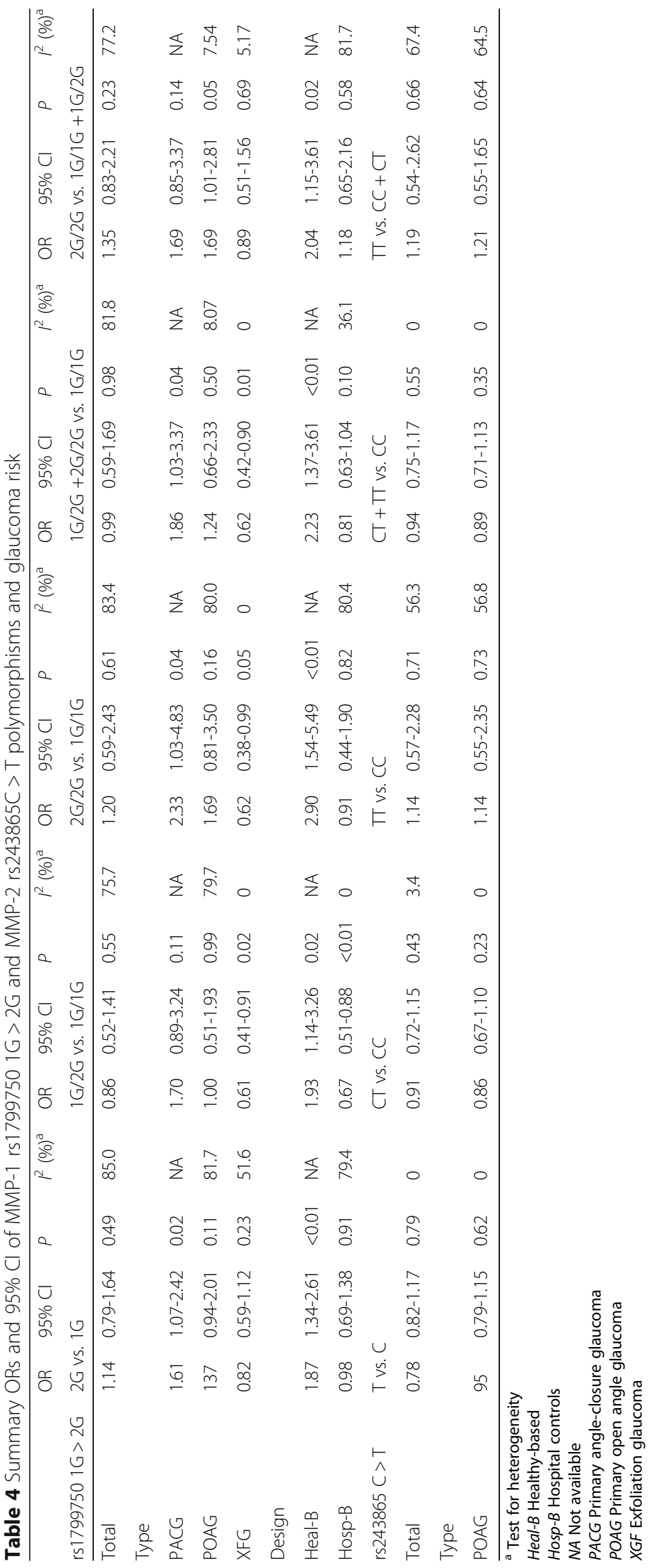




\section{Abbreviations}

95\% Cls: 95\% confidence intervals; AH: Aqueous humor; Cls: Confidence intervals; ECM: Extracellular matrix; HWE: Hardy-Weinberg equilibrium; IOP: Intraocular pressure; MMPs: Matrix metalloproteinases; ORs: Odds ratios; PRISMA: Preferred reporting items for systematic reviews and meta-analyses; SNPs: Single nucleotide polymorphisms; TIMPs: Tissue inhibitors of metalloproteinases

\section{Acknowledgements}

Not applicable.

\section{Funding}

This study was partly supported by the National Natural Science Foundation of China (81170993). The foundation had no role in study design, data collection and analysis, decision to publish, or preparation of the manuscript.

\section{Availability of data and materials}

All the data supporting our findings is contained within the manuscript.

\section{Authors' contributions}

Conceived and designed the study: M-YW, YW, and LZ; Acquisition of data: YZ and C-YL; Analysis and interpretation of data: C-YD and LP; Drafting the manuscript: M-YW and YW; Revising the manuscript critically for important intellectual content: $Y Z$ and $L Z$. All authors read and approved the final manuscript.

\section{Competing interests}

The authors declare that they have no competing interests.

\section{Consent for publication}

Not applicable

\section{Ethics approval and consent to participate}

Not applicable. No ethical issues were involved in this study given that our data were based on published studies. Written informed consent for participation and ethical approval has been provided by original studies. Thus, all investigations analyzed in this meta-analysis have been carried out in compliance with the Helsinki Declaration.

\section{Publisher's Note}

Springer Nature remains neutral with regard to jurisdictional claims in published maps and institutional affiliations.

\section{Author details}

${ }^{1}$ Stomatologic Hospital \& College, Anhui Medical University, Key Laboratory of Oral Diseases Research of Anhui Province, Hefei 230032, China. ${ }^{2}$ Department of Neurology, Center for Evidence-Based Medicine and Clinical Research, Taihe Hospital, Hubei University of Medicine, 32 South Renmin Road, Shiyan 442000, China. ${ }^{3}$ Department of Oral and Maxillofacial Surgery, State Key Laboratory Breeding Base of Basic Science of Stomatology \& Key Laboratory of Oral Biomedicine Ministry of Education, School and Hospital of Stomatology, Wuhan University, Wuhan, China. ${ }^{4}$ Department of Ophthalmology, Taihe Hospital, Hubei University of Medicine, Shiyan 442000, China. ${ }^{5}$ Department of Stomatology, Taihe Hospital, Hubei University of Medicine, 32 South Renmin Road, Shiyan 442000, China. 'Intensive Care Unit, Taihe Hospital, Hubei University of Medicine, Shiyan 442000, China.

Received: 29 April 2016 Accepted: 14 April 2017

Published online: 21 April 2017

\section{References}

1. Casson RJ, Chidlow G, Wood JP, Crowston JG, Goldberg I. Definition of glaucoma: clinical and experimental concepts. Clin Exp Ophthalmol. 2012:40:341-9.

2. Sommer A, Tielsch JM, Katz J, Quigley HA, Gottsch JD, Javitt JC, et al. Racial differences in the cause-specific prevalence of blindness in east Baltimore. N Engl J Med. 1991;325:1412-7.

3. Quigley HA, Broman AT. The number of people with glaucoma worldwide in 2010 and 2020. Br J Ophthalmol. 2006;90:262-7.
4. Wong TT, Sethi C, Daniels JT, Limb GA, Murphy G, Khaw PT. Matrix metalloproteinases in disease and repair processes in the anterior segment. Surv Ophthalmol. 2002;47:239-56.

5. Visse $\mathrm{R}$, Nagase $\mathrm{H}$. Matrix metalloproteinases and tissue inhibitors of metalloproteinases: structure, function, and biochemistry. Circ Res. 2003;92:827-39.

6. Maatta M, Tervahartiala T, Harju M, Airaksinen J, Autio-Harmainen H, Sorsa T. Matrix metalloproteinases and their tissue inhibitors in aqueous humor of patients with primary open-angle glaucoma, exfoliation syndrome, and exfoliation glaucoma. J Glaucoma. 2005;14:64-9.

7. Schlotzer-Schrehardt U, Lommatzsch J, Kuchle M, Konstas AG, Naumann GO. Matrix metalloproteinases and their inhibitors in aqueous humor of patients with pseudoexfoliation syndrome/glaucoma and primary open-angle glaucoma. Invest Ophthalmol Vis Sci. 2003;44:1117-25.

8. Niu YM, Du XY, Lu MY, Xu QL, Luo J, Shen M. Significant association between functional microRNA polymorphisms and head and neck cancer susceptibility: a comprehensive meta-analysis. Sci Rep. 2015:5:12972.

9. Niu Y, Yuan H, Shen M, Li H, Hu Y, Chen N. Association between cyclooxygenase-2 gene polymorphisms and head and neck squamous cel carcinoma risk. J Craniofac Surg. 2014;25:333-7.

10. Wang IJ, Chiang TH, Shih YF, Lu SC, Lin LL, Shieh JW, et al. The association of single nucleotide polymorphisms in the MMP-9 genes with susceptibility to acute primary angle closure glaucoma in Taiwanese patients. Mol Vis. 2006;12:1223-32.

11. Moher D, Liberati A, Tetzlaff J, Altman DG. Preferred reporting items for systematic reviews and meta-analyses: the PRISMA statement. Ann Intern Med. 2009;151:264-9. W64

12. Zeng $X$, Zhang $Y$, Kwong JS, Zhang C, Li S, Sun F, et al. The methodological quality assessment tools for preclinical and clinical studies, systematic review and meta-analysis, and clinical practice guideline: a systematic review. J Evid Based Med. 2015;8:2-10.

13. Higgins JP, Thompson SG. Quantifying heterogeneity in a meta-analysis. Stat Med. 2002;21:1539-58

14. Mantel N, Haenszel W. Statistical aspects of the analysis of data from retrospective studies of disease. J Natl Cancer Inst. 1959;22:719-48.

15. DerSimonian R, Laird N. Meta-analysis in clinical trials. Control Clin Trials. 1986;7:177-88.

16. Zhang L, Chen LM, Wang MN, Chen XJ, Li N, Huang YD, et al. The G894t, T-786c and 4b/a polymorphisms in Enos gene and cancer risk: a meta-analysis. J Evid Based Med. 2014;7:263-9.

17. Aung T, Yong VH, Lim MC, Venkataraman D, Toh JY, Chew PT, et al. Lack of association between the rs2664538 polymorphism in the MMP-9 gene and primary angle closure glaucoma in Singaporean subjects. J Glaucoma. 2008;17:257-8.

18. Cong Y, Guo X, Liu X, Cao D, Jia X, Xiao X, et al. Association of the single nucleotide polymorphisms in the extracellular matrix metalloprotease- 9 gene with PACG in southern China. Mol Vis. 2009:15:1412-7.

19. Mossbock G, Weger M, Faschinger C, Zimmermann C, Schmut O, Renner W, et al. Role of functional single nucleotide polymorphisms of MMP1, MMP2, and MMP9 in open angle glaucomas. Mol Vis. 2010;16:1764-70.

20. Awadalla MS, Burdon KP, Kuot A, Hewitt AW, Craig JE. Matrix metalloproteinase-9 genetic variation and primary angle closure glaucoma in a Caucasian population. Mol Vis. 2011;17:1420-4.

21. Shi H, Zhu R, Hu N, Shi J, Zhang J, Jiang L, et al. Association of frizzled-related protein (MFRP) and heat shock protein 70 (HSP70) single nucleotide polymorphisms with primary angle closure in a Han Chinese population: Jiangsu Eye Study. Mol Vis. 2013;19:128-34.

22. Micheal S, Yousaf S, Khan Ml, Akhtar F, Islam F, Khan WA, et al. Polymorphisms in matrix metalloproteinases MMP1 and MMP9 are associated with primary open-angle and angle closure glaucoma in a Pakistani population. Mol Vis. 2013;19:441-7

23. Gao XJ, Hou SP, Li PH. The association between matrix metalloprotease- 9 gene polymorphisms and primary angle-closure glaucoma in a Chinese Han population. Int J Ophthalmol. 2014:7:397-402

24. Markiewicz L, Majsterek I, Przybylowska K, Dziki L, Waszczyk M, Gacek M, et al. Gene polymorphisms of the MMP1, MMP9, MMP12, IL-1beta and TIMP1 and the risk of primary open-angle glaucoma. Acta Ophthalmol. 2013;91: e516-23.

25. Tsironi EE, Pefkianaki M, Tsezou A, Kotoula MG, Dardiotis E, Almpanidou P, et al. Evaluation of MMP1 and MMP3 gene polymorphisms in exfoliation syndrome and exfoliation glaucoma. Mol Vis. 2009;15:2890-5. 
26. Kaminska A, Banas-Lezanska P, Przybylowska K, Gacek M, Majsterek I, Szaflik J, et al. The protective role of the $-735 \mathrm{C} / \mathrm{T}$ and the $-1306 \mathrm{C} / \mathrm{T}$ polymorphisms of the MMP-2 gene in the development of primary open-angle glaucoma. Ophthalmic Genet. 2014:35:41-6.

27. Djordjevic-Jocic J, Zlatanovic G, Veselinovic D, Jovanovic P, Djordjevic V, Zvezdanovic L, et al. Transforming growth factor beta1, matrix-metalloproteinase-2 and its tissue inhibitor in patients with pseudoexfoliation glaucoma/syndrome. Vojnosanit Pregl. 2012;69:231-6.

28. De Groef L, Van Hove I, Dekeyster E, Stalmans I, Moons L. MMPs in the trabecular meshwork: promising targets for future glaucoma therapies? Invest Ophthalmol Vis Sci. 2013;54:7756-63.

29. Matusiewicz M, Neubauer K, Mierzchala-Pasierb M, Gamian A, Krzystek-Korpacka M. Matrix metalloproteinase-9: its interplay with angiogenic factors in inflammatory bowel diseases. Dis Markers. 2014;2014:643645.

30. Burduk PK, Bodnar M, Sawicki P, Szylberg L, Wisniewska E, Kazmierczak W, et al. Expression of metalloproteinases 2 and 9 and tissue inhibitors 1 and 2 as predictors of lymph node metastases in oropharyngeal squamous cell carcinoma. Head Neck. 2015;37:418-22.

31. Liu R, Chen L, Wu W, Chen H, Zhang S. Extracellular matrix turnover in coronary artery ectasia patients. Heart Vessels. 2016;31:351-59.

32. Navratilova Z, Zatloukal J, Kriegova E, Kolek V, Petrek M. Simultaneous up-regulation of matrix metalloproteinases 1, 2, 3, 7, 8, 9 and tissue inhibitors of metalloproteinases 1, 4 in serum of patients with chronic obstructive pulmonary disease. Respirology. 2012;17:1006-12.

33. Nga AD, Yap SL, Samsudin A, Abdul-Rahman PS, Hashim OH, Mimiwati Z. Matrix metalloproteinases and tissue inhibitors of metalloproteinases in the aqueous humour of patients with primary angle closure glaucoma - a quantitative study. BMC Ophthalmol. 2014;14:33.

34. Allan JA, Docherty AJ, Barker PJ, Huskisson NS, Reynolds JJ, Murphy G. Binding of gelatinases $A$ and $B$ to type-l collagen and other matrix components. Biochem J. 1995;309(Pt 1):299-306.

35. Shipley JM, Doyle GA, Fliszar CJ, Ye QZ, Johnson LL, Shapiro SD, et al. The structural basis for the elastolytic activity of the $92-\mathrm{kDa}$ and $72-\mathrm{kDa}$ gelatinases. Role of the fibronectin type Il-like repeats. J Biol Chem. 1996;271:4335-41.

36. Hu Z, Huo X, Lu D, Qian J, Zhou J, Chen Y, et al. Functional polymorphisms of matrix metalloproteinase- 9 are associated with risk of occurrence and metastasis of lung cancer. Clin Cancer Res. 2005;11:5433-9.

37. Zhang B, Henney A, Eriksson P, Hamsten A, Watkins H, Ye S. Genetic variation at the matrix metalloproteinase-9 locus on chromosome 20q12.2-13.1. Hum Genet. 1999;105:418-23.

\section{Submit your next manuscript to BioMed Central and we will help you at every step:}

- We accept pre-submission inquiries

- Our selector tool helps you to find the most relevant journal

- We provide round the clock customer support

- Convenient online submission

- Thorough peer review

- Inclusion in PubMed and all major indexing services

- Maximum visibility for your research

Submit your manuscript at www.biomedcentral.com/submit

Biomed Central 